УДК $536.66+543.86$

\title{
ОПРЕДЕЛЕНИЕ ТОКОФЕРОЛОВ КАК ЛИПИДНЫХ АНТИОКСИДАНТОВ В РАСТИТЕЛЬНЫХ МАСЛАХ И ЖИВОТНЫХ ЖИРАХ
}

\section{(C) Н.В. Сизова}

\author{
Институт химии нефрти Сибирского отделения Российской академии наук, \\ пр. Академический, 3, Томск, 634021 (Россия), e-mail: sizovaNV@mail.ru
}

Методом микрокалориметрии определено содержание витамина Е (токоферолов) в натуральных растительных маслах и жирах. Метод относится к кинетическим методам определения витамина Е, основанным на способности токоферола ингибировать реакции жидкофазного радикального окисления. На модельной реакции инициированного окисления кумола показано, что жирные масла тормозят радикальную реакцию с периодом индукции, пропорциональным содержанию токоферолов в масле. По экспериментальным кривым определено количественное содержание токоферолов в маслах, полученных разными технологическими способами.

Как показано в работе, количество токоферолов является показателем качества масла, поэтому предлагаемая методика определения токоферолов может быть использована для контроля способа получения, качества масла и присутствия синтетических антиоксидантов.

Ключевые слова: токоферол, антиоксиданты, растительные масла, определение, жидкофазное радикальное окисление.

\section{Введение}

Витамин Е - токоферол (ТФ) - называют витамином молодости и продолжения рода, что отражается в его названии, которое состоит из греческого слова tokos - потомство, и латинского ferre - приносить. Это название было дано всвязи с историей его открытия. В 1922 г. Evants и Dishop исследовали причины бесплодия у крыс, которые содержались на искусственном рационе. Введение в рацион апельсинового сока не излечивало крыс от бесплодия, а вот добавка листьев салата возвращала репродуктивные функции. Далее было обнаружено, что новый витамин содержится в большом количестве в зародышах злаков, растительных маслах, что витамин этот жирорастворим и имеет большое количество химических аналогов.

В настоящее время в понятие «витамин Е» включается большая группа природных веществ, которые обладают схожей биологической активностью. Кроме самого распространенного в природе и наиболее активного $\alpha$-токоферола, известны его 11 гомологов и стереоизомеров, все они в настоящее время выделены из растительных масел или получены синтетически. При комнатной температуре токоферолы представляют собой маслянистую жидкость светло-желтого цвета, не растворимую в воде, растворимую в хлороформе, серном эфире, петролейном эфире, слабее в этиловом спирте и ацетоне $[1,2]$.

Биологическая ценность растительных масел определяется набором жирных кислот, особенно ценными считаются полиненасыщенные кислоты и жирорастворимые витамины. В таблице 1 приведены данные о содержании витамина Е в продуктах. Основное хранилище витамина Е - это семена, косточки, орехи и соответственно все жирные масла, максимальное количество обнаружено в масле пшеничных зародышей. Витамин Е достаточно термически устойчив, нагревание до $170{ }^{\circ} \mathrm{C}$ на воздухе и $220{ }^{\circ} \mathrm{C}$ в вакууме не лишает его биологической активности. Поэтому приготовление пищи в кипящей воде не приводит к потере

Сизова Наталия Витальевна - научный сотрудник лаборатории физико-химических методов исследования, кандидат химических наук, тел.: (3822) 49-25-51, факс: (3822) 49-14-57, e-mail: sizovaNV@ mail.ru токоферолов, а вот жарки в разогретом растительном масле следует избегать. 
Таблица 1. Содержание токоферолов в продуктах (мг\% - количество мг в 100 г) $[1,2]$

\begin{tabular}{l|c|l|c}
\hline \multicolumn{1}{c|}{ Продукт } & Содержание, мг\% & \multicolumn{1}{c}{ Продукт } & Содержание, мг\% \\
\hline Зерно пшеничное & 0,9 & Масло из пшеничных зародышей & $200-300$ \\
Мука пшеничная высшего сорта & 0,03 & Масло хлопковое & $70-100$ \\
Мука пшеничная первого сорта & 1,5 & Масло подсолнечное & $50-75$ \\
Отруби мелкие & 3,2 & Масло кукурузное & $10-23$ \\
Отруби крупные & 0,3 & Масло соевое & $75-170$ \\
Пшеничные зародыши & 15,8 & Масло арахисовое & 14 \\
& & Масло кокосовое & $3-8$ \\
\hline
\end{tabular}

В маслах токоферолы можно определить по специфическим спектрам электронного поглощения с максимумом для $\alpha$-токоферола 292 нм, $\beta$-токоферола 297 нм, $\delta$ - и $\gamma$-токоферола 298 нм. В заводских лабораториях применяется хроматографический способ определения витамина Е по ГОСТу [3]. Известны методики, позволяющие определять токоферол как антиоксидант, так как в модельных реакциях он ведет себя как классический ингибитор радикальных процессов [4]. Доказано, что токоферолы выполняют функцию натурального антиоксиданта [5], на этом основании врачи рекомендуют увеличить употребление витамина Е для нормализации повышенного окисления липидов, которое является процессом, сопровождающим многие заболевания.

Данные по содержанию витамина Е для многих масел устарели, иногда результаты измерений явно ошибочны. Например, в работе [6] для масла пшеничных зародышей приводится завышенное количество токоферолов 1200 мг\%, по многочисленным измерениям оно составляет 280-350 мг\%. В этой же работе для рыжикового масла количество токоферолов приводится 785-821 мг\%, нами определено двумя независимыми методами 100-110 мг\% [7].

В настоящее время совершенствуются технологии получения масел, сейчас на рынке продаются масла, полученные холодным или горячим прессованием, разной степени очистки. Поэтому выбор масла для диеты или подбор ингредиента для БАД или косметического крема, масляных лекарственных форм важен в том числе с точки зрения содержания токоферолов, так как он является метчиком качества и свежести масла [7].

В ранее опубликованных работах мы показали, что применяемый нами метод микрокалориметрии позволяет достоверно определить токоферол-антиоксидант [8-10]. Эти данные хорошо совпадают с данными, полученными и кинетическими, и хроматографическими методами [8]. Также мы показали, что как любой антиоксидант, токоферол расходуется при нагревании, хранении масла, поэтому его высокая концентрация свидетельствует о свежести масла [10]. Константа скорости реакции взаимодействия токоферолпероксирадикал, которая характеризует активность антиоксиданта, не уступает по величине константы для mрет-бутилфенолов (БОА, БОТ) [8], но защитить масло от прогорания токоферол не в состоянии.

В настоящей работе мы измерили содержание антиоксиданта-токоферола в маслах одного вида от различных производителей, полученных разными технологиями, и в жирах животных. Метод позволяет также обнаружить наличие экзогенных антиоксидантов.

\section{Объекты исследования}

В работе использовали масла, приобретенные в магазинах, аптечных сетях или любезно предоставленные производителями. Несколько образцов масел произведены холодным прессованием Томским предприятием ООО «Лаборатория Рузаева»и являются образцами сыродавленных масел, не содержащих синтетических примесей и не подвергавшихся рафинации и дезодорации.

Масло рыжиковое (Camelina sativa) предоставлено ООО ПКП «Провансаль», г. Томск, отличается большим количеством полиненасыщенных жирных кислот и после дезодорации требует дополнительной защиты от окисления, что достигается добавкой комплексного антиоксиданта. Поэтому в работе исследовались три образца масла - нерафинированное, рафинированное дезодорированное, рафинированное дезодорированное с добавкой антиоксиданта «Антранцин 33».

Образцы экстракционного и прессованного масла виноградных косточек (Vitis vinifera L.) предоставлены Институтом винограда и вина «Магарач», г. Ялта.

Жиры животные топленые получены от охотников, занимающихся добычей животных в Томской области, второй образец барсучьего жира куплен в аптеке (ООО «Багира», Оренбург). 
Масло кокосовое двух производителей привезено из Таиланда, один образец куплен в аптечной сети, другой - в магазине «Nature Product».

\section{Метод исследования}

Измерения осуществлялись на микрокалориметре МКДП-2, произведенном в ИХН СО РАН по оригинальной конструкции, методика измерений описана в работе [8]. Метод микрокалориметрии относится к кинетическим методам и основан на регистрации теплоты модельной реакции инициированного окисления кумола в присутствии добавок натуральных масел. При наличии активного антиоксиданта данный метод позволяет оценивать активность ингибиторов - константу $k_{7}$ - по приведенной ниже формуле (1) и количество антиоксидантов в смеси сложного состава (2).

$$
\mathrm{W}_{\mathrm{t}}=\Delta H \cdot V \cdot k_{2} / k_{7} \cdot[\mathrm{RH}] \cdot[1 /(\tau-t)],
$$

где $\Delta H$ - энтальпия изучаемого процесса, равная $111 \pm 3$ кДж/моль [4]; $V$ - объем реакционной смеси, л. Подставляя известные значения концентрации кумола $[\mathrm{RH}]_{60}=6,9$ моль/л, объема кумола $V=4$ мл; $k_{2}=1,75$ л/моль·с [9] в приведенное выше выражение, рассчитываем $k_{7}$.

Определяемая константа скорости ингибирования $k_{7}$ относится к взаимодействию пероксирадикала с токоферолом (реакция II ):

$$
\begin{gathered}
\mathrm{RH}+\mathrm{RO}_{2}^{\cdot} \stackrel{\mathrm{k}_{2}}{\longrightarrow} \mathrm{ROOH}+\mathrm{R}^{\cdot} \\
\mathrm{InH}+\mathrm{RO}_{2}^{\cdot} \stackrel{\mathrm{k}_{7}}{\longrightarrow} \mathrm{ROOH}+\mathrm{In}^{\circ}
\end{gathered}
$$

Для натуральных растительных масел константы скорости ингибирования для токоферолов изменяются в пределах $k_{7}=(1,4-6,8) \cdot 10^{4}$ моль/л·с [9]. На примерах рыжикового и рапсового масел показано, что более высокое значение имеет константа скорости ингибирования для нерафинированного масла $6,2 \cdot 10^{4}$ л/моль·с, чем для рафинированного дезодорированного - $1,4 \cdot 10^{4}$ л/моль·с [9].

Если ингибитор эффективный, то в таком случае наблюдается период индукции $\tau$ (сек), который связан со скоростью инициирования $w_{\mathrm{i}}$ (л/моль·c) и начальной концентрацией антиоксидантов $[\mathrm{AO}]_{0}$ (моль/л) следующей формулой:

$$
\tau=f n \frac{[\operatorname{In} H]_{0}}{w_{i}}
$$

По периоду индукции реакции окисления кумола можно оценить концентрацию антиоксидантов для сложных смесей природного происхождения. Ограничение метода - растворимость исследуемых фракций в кумоле; из объектов, выделенных из растительного сырья, это жирные, эфирные масла, липидные фракции растений, углекислотные экстракты. На рисунке 1 приведен пример экспериментальной кривой тепловыделения в присутствии рыжикового масла, показано, что при наличии сильного антиоксиданта-токоферола регистрируется период индукции. Как известно, эфирные масла не содержат токоферол, поэтому в присутствии эфирного масла тысячелистника мы наблюдаем понижение скорости окисления модельной реакции (рис. 2). На примере углекислотных экстрактов мы показали, что объекты значительно отличаются по силе АО-активности [11] в зависимости от исходного сырья при одинаковой технологии экстракции.

В своих расчетах мы принимаем токоферол за сильный ингибитор с одной функциональной группой $n=1$ и стехиометрическим коэффициентом ингибирования $f=2$, и из периода индукции рассчитаем концентрацию токоферолов. Так как в маслах присутствуют 11 гомологов токоферола, то для расчетов мы усреднили вес четырех основных гомологов ( $\alpha-, \beta-, \gamma-, \sigma-)$, получив средний вес 416 у.е., что на $3 \%$ отличается от веса наиболее распространенного и активного гомолога - $\alpha$-токоферола. Как показано нами ранее, константы скорости ингибирования окисления для всех масел (рыжиковое, сурепное, рапсовое, кедровое) отличаются незначительно и составляют $k_{7}=(1,4-6,8) \cdot 10^{4}$ моль/л·с [9]. 


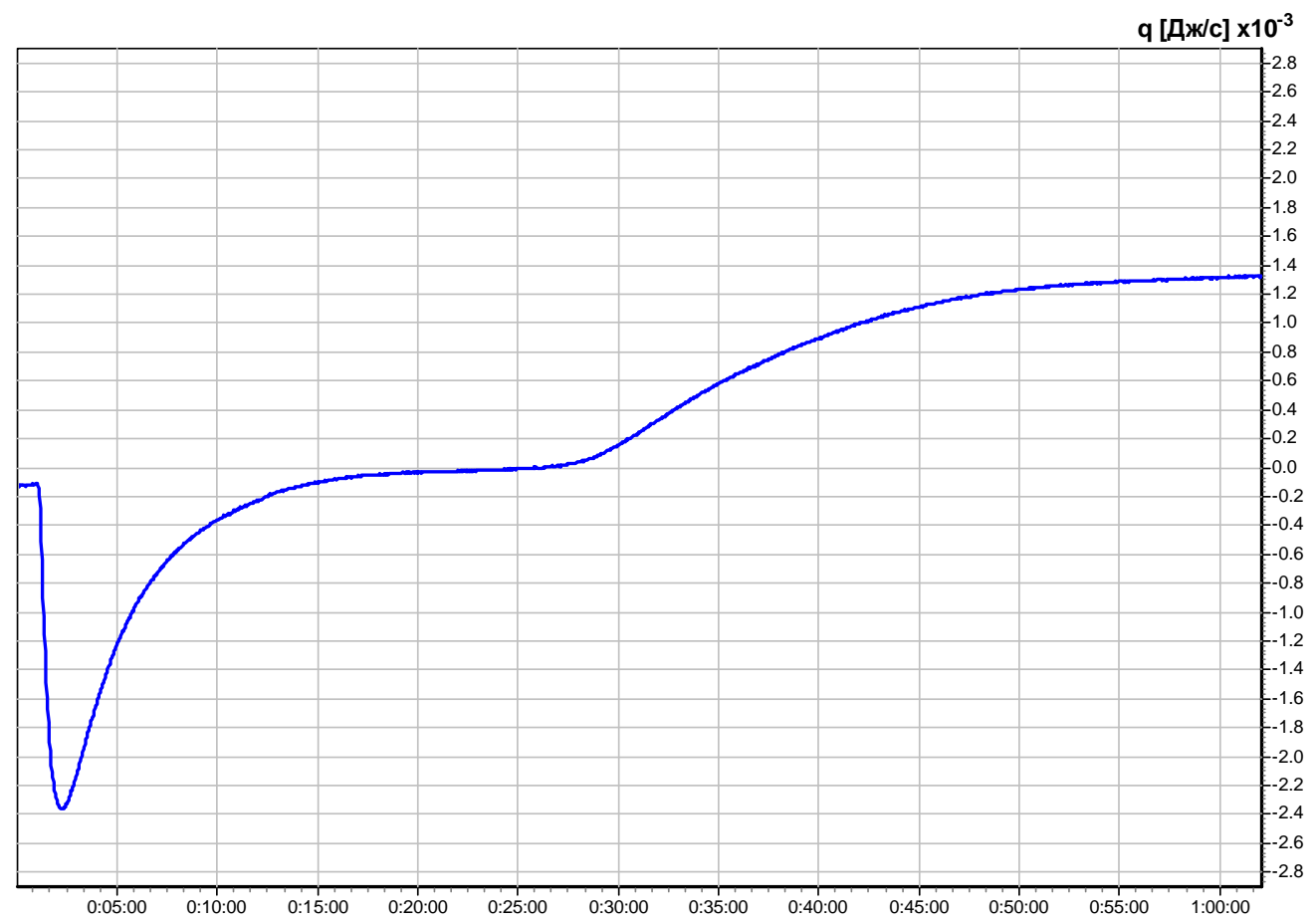

Рис.1. Тепловыделение модельной реакции окисления кумола (кислород, $\mathrm{t}=60{ }^{\circ} \mathrm{C}$, скорость инициирования $w_{\mathrm{i}}=6,8 \cdot 10^{-8}$ л/(моль с)) в присутствии масла рыжикового дезодорированного, $C=28,55$ г/л. АИБН 4,6 мг

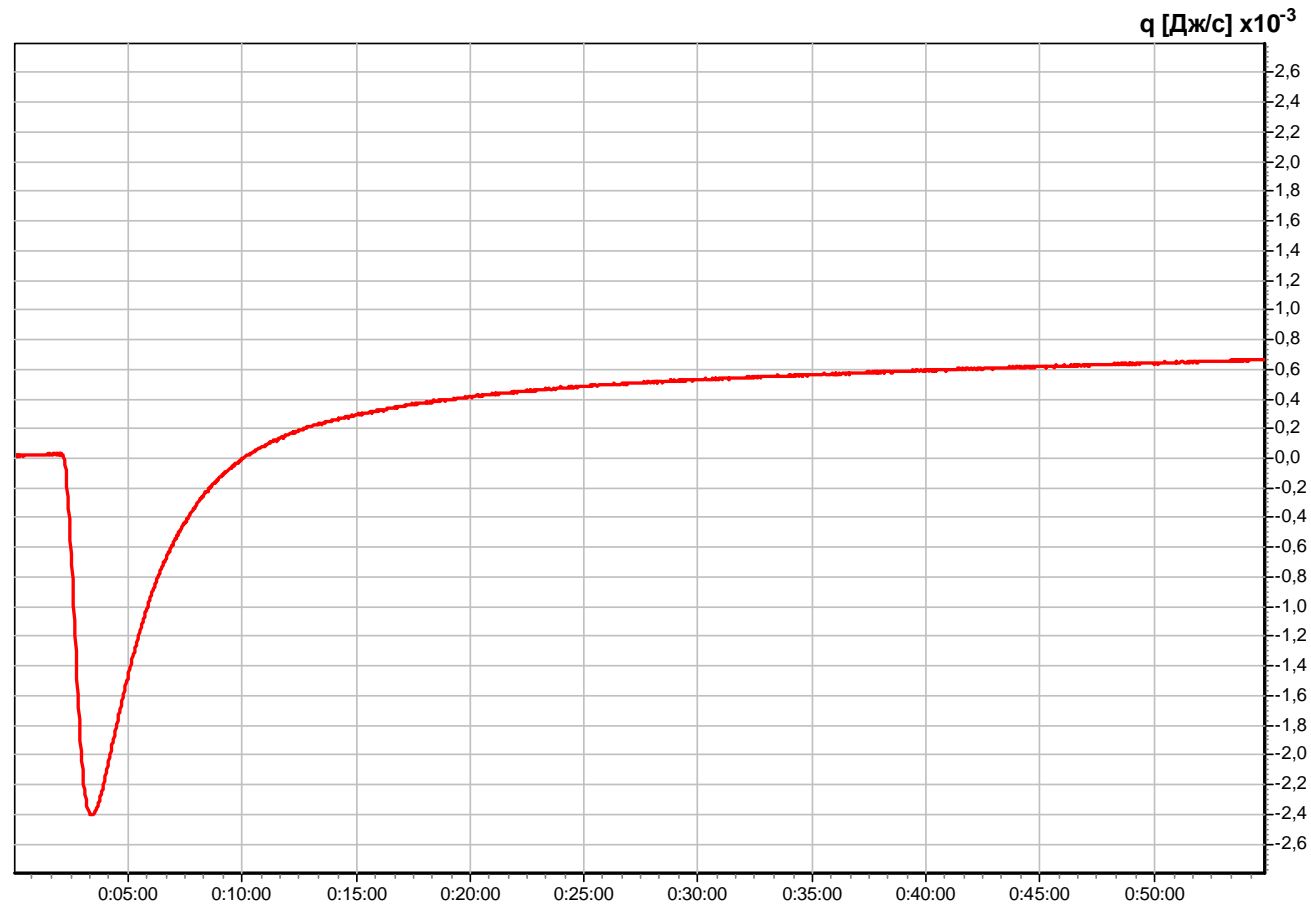

Рис. 2. Тепловыделение модельной реакции окисления кумола (кислород, $t=60{ }^{\circ} \mathrm{C}$, скорость инициирования $w_{\mathrm{i}}=6,8 \cdot 10^{-8}$ л/(моль с)) в присутствии эфирного масла тысячелистника. Томск. $C=0,9$ г/л, скорость окисления 1,48 $10^{-6}$ моль/л с, 4,2 мг АИБН, 4 мл кумола, кислород

\section{Результаты и обсуждение}

Содержание гомологов токоферолов в маслах и жирах служит одним из признаков качества масла, способа получения и очистки. Например, как видно из таблицы 2, подсолнечное и кедровое масла ООО «Лаборатория Рузаева», полученные способом холодного прессования, превышают на 10-20\% по содержанию 
витамина Е масла крупнотоннажного промышленного производства, особенно если масло рафинировано. На образцах подсолнечного, рыжикового и рапсового масла показано, что в процессе рафинации и дезодорации масла теряется до 10\% витамина Е. Содержание токоферолов в масле зародышей пшеницы, по справочным данным, должно составлять 200-300 мг\% [1, 2], из исследованных масел у одного производителя (Новосибирск) содержание витамина Е соответствует справочным данным, а у другого (Москва) практически в 3 раза меньше, что свидетельствует о фальсификации. Изученные в работе два образца абрикосового, льняного масел от разных производителей практически одинаковы по качеству. Масло виноградных косточек, полученное прессованием, более богато токоферолами, чем экстракционное масло.

Отдельный интерес представляют жиры животные, которые в народной медицине издавна применяются как наружное и внутреннее средство для лечения простудных заболеваний. В последние годы жиры животные включаются в рецептуру лечебных и массажных кремов. Так как жир для животных является депо для питательных веществ и жирорастворимых витаминов, то логично предположить, что витамин Е также должен накапливаться в подкожном жировом слое. Витамин Е поступает в животный жир с пищей из орехов, ягод, и его количество в урожайные на орех годы будет повышено. Как видно из таблицы 2, жиры норковый, барсучий и медвежий содержат примерно по 10-15 мг\% витамина Е. В одном образце барсучьего жира присутствует антиокислитель, поэтому пересчет на токоферолы дает завышенное значение токоферолов.

Таблица 2. Содержание токоферолов в растительных маслах и животных жирах (мг\% - мг в 100 г).

Определение токоферола-антиоксиданта в маслах проведено на модельной реакции окисления кумола (кислород, $t=60^{\circ} \mathrm{C}$, скорость инициирования $w_{\mathrm{i}}=6,810^{-8}$ л/(моль с))

\begin{tabular}{|c|c|c|}
\hline Сорт масла, производитель & {$[\mathrm{AO}] \cdot 10^{-3}$, моль $/$ кг } & Содержание токоферола, мг\% \\
\hline 1 & 2 & 3 \\
\hline Кедровое масло (Pinus sibirica) & & \\
\hline ООО «Дары природы», Томск & 1,00 & 43 \\
\hline ООО «Сибэкопродукт», Томск & 1,26 & 54 \\
\hline ПКП «Лазурин», Новосибирск & 1,30 & 55 \\
\hline ООО «Лаборатория Рузаева», Томск & 1,44 & 61 \\
\hline Подсолнечное масло (Helianthus) & & \\
\hline ОАО «Губинское масло» & 1,55 & 67 \\
\hline «Алтай», Барнаул & 1,64 & 71 \\
\hline «Полдень», ООО ПКП «Провансаль», Томск & 2,00 & 86 \\
\hline ООО «Лаборатория Рузаева», Томск & 2,18 & 90 \\
\hline Масло зародышей пшеницы (Triticum) & & \\
\hline ООО «СибТар», Новосибирск & $6,49-6,99$ & $300-350$ \\
\hline ООО «Биаск», Москва & 2,31 & $100-105$ \\
\hline Масло рыжиковое (Camelina sativa) & & \\
\hline ООО ПКП «Провансаль», Томск & & \\
\hline Нерафинированное масло & 2,73 & 117 \\
\hline Рафинированное дезодорированное масло & 2,39 & 102 \\
\hline $\begin{array}{l}\text { Рафинированное дезодорированное масло с добавкой ан- } \\
\text { тиоксиданта «Антранцин 33» }\end{array}$ & 2,77 & Эквивалентно 119 \\
\hline Рапсовое (Brassica napus oleifera) масло & & \\
\hline ООО ПКП «Провансаль», Томск & & \\
\hline Нерафинированное масло & 1,97 & 85 \\
\hline Рафинированное масло & 1,77 & 77 \\
\hline $\begin{array}{l}\text { Масло виноградных косточек (Vitis vinifera L.) } \\
\text { (Институт винограда и вина «Магарач», Ялта) }\end{array}$ & & \\
\hline Экстракционное & 2,01 & 88 \\
\hline Прессованное & 2,56 & 106 \\
\hline Масло грецкого ореха (Juglans regia L.) & & \\
\hline ООО «Лаборатория Рузаева», Томск & 1,24 & $58-53$ \\
\hline $\begin{array}{l}\text { Масло конопляное Cannabis sativa } \\
\text { ООО «Лаборатория Рузаева», Томск }\end{array}$ & 1,99 & 85 \\
\hline Масло льняное Linum usitatissimum L., Новосибирск & 2,01 & $70-86$ \\
\hline $\begin{array}{l}\text { Масло льняное Linum usitatissimum L., } \\
\text { ООО «Лаборатория Рузаева», Томск }\end{array}$ & 1,60 & $73-77$ \\
\hline Кокосовое масло (Coconut oil), «Nature Product», Таиланд & 0,65 & $25-28$ \\
\hline
\end{tabular}


Окончание таблиць 2

\begin{tabular}{|c|c|c|}
\hline 1 & 2 & 3 \\
\hline Кокосовое масло (аптечная сеть) & 0,11 & $5-7$ \\
\hline Абрикосовое масло (Prunus armeniaca) & & \\
\hline ООО «Дары природы», Томск & 1,81 & 78 \\
\hline «Биаск», Москва & 1,84 & 79 \\
\hline $\begin{array}{l}\text { Масло персиковое (Persica mill.), } \\
\text { ОАО «Фармацевтическая фабрика Санкт-Петербурга», } \\
\text { Санкт-Петербург }\end{array}$ & 2,31 & 102 \\
\hline $\begin{array}{l}\text { Миндальное масло (Amygdalus communis), } \\
\text { ООО «Биаск», Москва }\end{array}$ & 1,15 & 49 \\
\hline Жир медвежий топленый, Томск & 0,33 & 14,0 \\
\hline Жир норковый топленый, Томск & 0,30 & 13,0 \\
\hline Жир барсучий топленый, Томск & 0,21 & 9,0 \\
\hline ООО «Багира», Оренбург & 1,3 & $\begin{array}{c}\text { Эквивалентно 55 } \\
\text { (добавка антиоксиданта) }\end{array}$ \\
\hline
\end{tabular}

Для предотвращения окисления в образец рыжикового масла по технологии производителя добавлен антиоксидант «Антранцин 33», при этом наша методика определяет увеличение концентрации антиоксиданта на $15 \%$. Поэтому описанная методика применима для установления добавок синтетических антиоксидантов.

Витамин Е может выполнять роль антиоксиданта, но его эффективности недостаточно для полной остановки процесса окисления. В нашей работе [10] мы показали, что в процессе ускоренного окисления жирных масел при повышенной температуре $\left(50{ }^{\circ} \mathrm{C}\right)$ в течение 30 дней концентрация токоферолов снижается до нулевой. При этом масла теряют текучесть и превращаются в вязкие пленки. Как любой антиоксидант, витамин Е расходуется в процессе хранения жирного масла. В реальных условиях хранения масел в бытовых холодильниках окисление масел происходит медленно, и в течение срока годности, гарантированного производителем, продукты окисления присутствуют в пределах нормы. Однако если появляются органолептические признаки окисления масла - неприятный запах, привкус горечи, повышается вязкость, то такое масло не рекомендуется употреблять в пищу.

\section{Заключение}

В работе измерено содержание витамина Е в натуральных маслах и жирах, применяемых в пищевой, косметической и фармацевтической промышленности. Установлено, что в маслах, полученных из одного вида сырья, в зависимости от способа производства содержание токоферолов может отличаться на 25-30\%. Суммируя данные, можно сделать вывод, что высокое содержание витамина Е в маслах одного вида может служить признаком бережной технологии получения масла, и это увеличивает его пищевую ценность. Применяемый в работе метод МК позволяет быстро и безошибочно определять качество и свежесть масла по суммарной концентрации антиоксидантов, из которых рассчитывается содержание витамина Е, а также определять присутствие экзогенных антиоксидатов.

Автор выражает благодарность Леониду Николаевичу Рузаеву за предоставление масел кедрового, конопляного, льняного, масла грецкого ореха; Инне Владимировне Черноусовой (Институт винограда и вина «Магарач», Ялта) за предоставление образцов масел виноградных косточек; ООО ПКП «Провансаль» за предоставление образиов нерафинированных и рафинированных дезодорированных масел рыжикового, рапсового, подсолнечного.

\section{Список литературы}

1. Витамины / под ред. В.В. Смирнова. М.,1974. 128 с.

2. Калинин Ф.Л., Лобов В.П., Жидков В.А. Справочник по биохимии. Киев, 1971. 1013 с.

3. Масла растительные. Методы определения массовых долей витаминов А и Е. ГОСТ 30417-96. М., 1997.

4. А.c. 761902 (СССР). Способ количественного определения ингибитора-токоферола в подсолнечном масле / Радченко Л.М., Цепалов В.Ф., Кончаловская М.Е., Шмидт А.А., Пастухова В.И., Козлова З.Г. / БИ. 1980. №33.

5. Бурлакова Е.Б., Храпова Н.Г. Перекисное окисление липидов мембран и природные антиоксиданты // Успехи химии. 1985. T. LIV, вып. 9. С. 1540-1558. 
6. Шиков А.Н., Макаров В.Г., Рыженков В.Е. Растительные масла и масляные экстракты: технология, стандартизация, свойства. М., 2004. 263 с.

7. Сизова Н.В., Пикулева И.В., Чикунова Т.М. Жирнокислотный состав масла Camelina sativa (L.) Crantz и выбор оптимального антиоксиданта // Химия растительного сырья. 2003. №2. С. 27-31.

8. Патент №224205 (РФ). Способ количественного определения токоферолов в растительных маслах / Великов А.А., Сизова Н.В. // БИ №9, 2005.

9. Сизова Н.В., Андреева Н.Ю. Определение витамина Е в растительных маслах методом микрокалориметрии // Химико-фармацевтический журнал. 2007. Т. 41, №6. С. 49-52.

10. Сизова Н.В. Снижение концентрации токоферолов в процессе окисления жирных масел // Химия растительного сырья. 2009. №1. С. 117-119.

11. Сизова Н.В., Попова И.Ю. Содержание антиоксидантов в экстрактах растительного сырья, полученных сверхкритической экстракцией // Химико-фармацевтический журнал. 2006. Т. 40. №4. С. 29-33.

Поступило в редакичию 18 января 2012 2.

\section{Sizova $N . V$. THE VITAMIN E CONTENT IN EDIBLE AND PHARMACEUTICAL OILS}

Institute of Petroleum Chemistry SB RAS, Akademichesky pr., 4, Tomsk, 634021 (Russia), e-mail: sizovaNV@mail.ru

The content of vitamin E (tocopherols) in natural vegetable oils used in alimentary, cosmetic and pharmaceutical products has been determined using microcalorimetry.

As is shown in the work, the quantity of tocopherols is an oil quality index. The high content of vitamin $\mathrm{E}$ is determining for choice of oil as ingredient of creams and oil dosage forms since it is an important fat-soluble vitamin. The kinetic method for the determination of vitamin $\mathrm{E}$ based on the capability of the tocopherol to inhibit the reactions of radical liquid-phase oxidation was used in the work.

The proposed method for tocopherol determination can be used to control the oil quality and the presence of synthesized antioxidant additions.

Keywords: tocopherol, antioxidants, oils, determining liquid phase oxidation radical.

\section{References}

1. Vitaminy/pod red. V.V. Smirnova. [Vitamins. Ed. V.V. Smirnov]. Moscow, 1974, 128 p. (in Russ.)

2. Kalinin F.L., Lobov V.P., Zhidkov V.A. Spravochnik po biokhimii. [Handbook of Biochemistry]. Kiev, 1971,1013 p. (in Russ.)

3. GOST 30417-96. Masla rastitel'nye. Metody opredeleniia massovykh dolei vitaminov A $i$ E. [GOST 30417-96. Vegetable oils. Methods for determining concentrations of vitamins A and E]. Moscow, 1997. (in Russ.)

4. Patent 761902 (SU). 1980. (in Russ.)

5. Burlakova E.B., Khrapova N.G. Uspekhi khimii, 1985, vol. LIV, no. 9, pp. 1540-1558. (in Russ.)

6. Shikov A.N., Makarov V.G., Ryzhenkov V.E. Rastitel'nye masla i maslianye ekstrakty: tekhnologiia, standartizatsiia, svoistva. [Vegetable oils and oil extracts of: technology, standardization, properties]. Moscow, 2004, 263 p. (in Russ.)

7. Sizova N.V., Pikuleva I.V., Chikunova T.M. Khimiia rastitel'nogo syr'ia, 2003, no. 2, pp. 27-31. (in Russ.)

8. Patent №224205 (RU). 2005. (in Russ.)

9. Sizova N.V., Andreeva N.Iu. Khimiko-farmatsevticheskii zhurnal, 2007, vol. 41, no. 6, pp. 49-52. (in Russ.)

10. Sizova N.V. Khimiia rastitel'nogo syr'ia, 2009, no. 1, pp. 117-119. (in Russ.)

11. Sizova N.V., Popova I.Iu. Khimiko-farmatsevticheskii zhurnal, 2006, vol. 40, no. 4, pp. 29-33. (in Russ.) 
